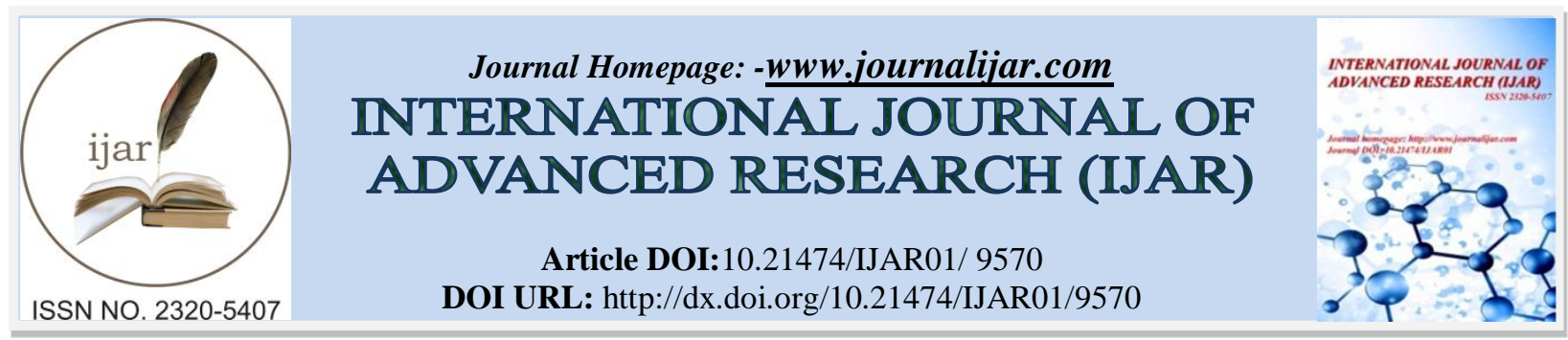

RESEARCH ARTICLE

\title{
GLOBALIZATION, MULTIMODAL COMPOSITION, AND FEMINISM.
}

Arjun Kumal.

Tribhuvan University.

\section{Manuscript Info}

Manuscript History

Received: 12 June 2019

Final Accepted: 14 July 2019

Published: August 2019

Key words:-

Globalization, Neoliberalism, Multimodal Composition, Feminism.

\begin{abstract}
Globalization is a complex phenomenon incorporating myriads socioeconomic and cultural implications. The proponents of globalization only posit its benefits and cite instances of how the global traffic of ideas and capital has benefitted all nation states. Its critics are overtly critical about it. They argue that globalization is a neo-colonization project used by the rich and the powerful states to further hegemonize the weaker nation sates. In other words, the rewards of globalization are reaped only by powerful states. There are, however, some who adopt a middle path to show what works with globalization and what doesn't, and that it has its own pros and cons. This paper will lean on scholars like Amartya Sen, John Micklethwait and Adrian Wooldridge, and John L. McKnigh among others to analyze socio-economic dimensions of globalization, particularly paying attention to multimodal composition, and feminism and how globalization is impacting the way teaching learning takes place in classrooms across the globe.
\end{abstract}

Copy Right, IJAR, 2019,. All rights reserved.

\section{Introduction:-}

The idea of "globalization" has been contested. While some scholars support it wholeheartedly, others decry it vehemently. Still others try to find the middle path. Therefore, it is important to explore all the competing ideas before rooting for one of them. This paper will primarily look into the thoughts of John Micklethwait and Adrian Wooldridge to show the positive view on globalization, the essay of John Gray for the antagonistic view on globalization, and the view of Amartya Sen to exhibit the middle path. This article will further develop on the equitable aspect of globalization, including ideas of Ashok Bhusal and Suresh Lohani regarding the effective deployment of feminist and multimodal theories in the writing classroom. Though scholars define globalization differently, probably what most would agree comes from Frank J. Lechner and John Boli in The Globalization Reader. Their definition is catholic not parochial - they look into not only the economy but also culture. They assert:

Globalization (thus) involves growing diffusion, expanding interdependence, more transnational institutions, and an emerging world culture and consciousness - all aspects of connectedness at the heart of globalization, all elements of the world society globalization is creating. (p. 2)

To bolster the definition of globalization by Frank J. Lechner and John Boli, Manfred, B. Steger in Globalization: A Very Short Introduction defines globalization as "a multi-dimensional set of social processes that resists being confined to any single thematic framework."( ix). He further states, "the transformative powers of globalization reach deeply into the economic, political, cultural, technological, and ecological dimensions of contemporary social 
life" (ix). Scholars may agree on the definition of globalization but they certainly are poles apart on their position on globalization. For most globalization is connectedness, interdependency at the global level. However, this agreement fizzles out when it comes to taking a position. Their positions vary from very positive to very negative, and some try to maintain the golden mean. One major school of thought on globalization is very positive. I find this in the likes of John Micklethwait and Adrian Wooldridge. In their essay "The Hidden Promise: Liberty Renewed," they claim that globalization creates prosperity and gives people liberty unknown to man before. They contend:

Globalization clearly benefits producers by giving them greater choice over raw materials, production techniques, and human talent ...benefits consumers by providing them with better goods at better prices. Globalization increases efficiency and thus prosperity. (p. 13)

Not only does globalization produce greater efficiency and prosperity, it also opens up societies and reduces the "tyranny of place" by extending the "idea of liberty" to everyone. In business and commerce, free trade allows business people to bypass intervening officials by carrying their money and operations abroad. Furthermore, globalization has materialized dreams of millions of people all over the world to be richer than they were before. Further, Micklethwait and Wooldridge claim that globalization has offered unlimited opportunities, and rewarded millions of people all over the world. It has enabled people to transform their dreams into realities. This makes globalization worth defending on more than just parochial economic basis. So, they declare that "globalization is delivering enough of that dream to make it worth pressing forward" (p. 17).

Indeed, neoliberalism fueled by globalization has definitely opened up new avenues for co-operation, created global markets, helped in cultural assimilation, and collapsed physical distances between different locations in the world. Deepika Bahri (2008), for example, quotes British Telecom's catchphrase slogan that "Geography is history" and argues that "traditional cultural boundaries are ruptured and redrawn." Bahri further contends how "neoliberalism may evolve and adapt with times, but it is here to stay." And with the revolution in technology and the slippery nature of this phenomenon, Bahri holds that a world that is rife with ever increasing differences is showcasing different facets of its intricate everyday picture (p.528). This explains how things are changing for everyone and that the synergy of globalization should be tapped to serve the interests of all. Globalization may follow different trajectories and experience many upheavals along the way, but it is here to stay.

Equally strong is the negative voice against globalization. This school of thought sees globalization primarily as a "Utopian" economic force, an origin of the West that imposes an unjust and unequal capitalist system on the world, producing damaging results to local cultures and democratic self-control. A renowned champion of this school of thought is a British economist John Gray. Gray believes that incorporating the world's economies into a single global free market is a "Utopia that can never be realized." He perceives that its pursuit has already "produced social dislocation and economic and political instability on a large scale" (p.26). Moreover, he says the free markets have in the United States "contributed to social breakdown on a scale unknown in any other developed country" (p.26). He also asserts that the Utopia of global free market inflicts "sufferings" on man that "will rival" "the human cost" incurred by communism over time (p. 26). For all these reasons, Gray calls current push for global free market "the false dawn" (p. 28).

Some even look at the downsides of globalization by examining the rhetoric employed by some powerful global financial institutions. The rhetoric of the giant financial organizations such as the World Bank or the IMF is similar to that of the bereavement counsellors as advanced by john L. McKnigh who argues that the imperialist ideology seems to disregard the native (indigenous) values and impose some "technical solutions", which do little but worsen the situation. Joseph E Stieglitz (2002) former chief economist at the World Bank, in "Globalism's Discontents" argues that "the IMF has pushed (bad) economic policies without broader vision of the society or the role of economics within the society" (p. 16). He maintains that such organizations hold the fallacious view that they in the north know what works best for these countries in the East. Stieglitz's claims boil down to economic globalization turning out to be unjust, undemocratic and disadvantageous to the developing nations, and thus a new economic agenda and global governance is needed. What I see building on Stilglitz's outlook is Duggan's view that "the most successful ruse of neoliberal dominance in both global and domestic affairs is the definition of economic policy is primarily a matter of neutral, technical expertise" (The Twilight of Equality, XIV). Their economic policies fail to incorporate the cultural practices, and view it as purely technical business, in which they have the mastery, and thus the policies simply fail to deliver. Thus to the critics of globalization, globalization which propels neo-liberalism, 
does little to improve the lives of the marginalized since it is basically designed to serve the interests of the rich and the powerful.

I, on account of my positionality of a third world resident, often tend to nurture a pessimistic outlook on globalization since I have not seen my country reap its said benefits. Rachel C Riedner (2015) states that "as an economic and political practice, neoliberalism means the global expansion of markets and service economies, the upward distribution of wealth, and the withdrawal of state services." (p.61). In fact, with Nepal's embracing of neoliberal values, our trade deficits have increased at unprecedented rate, and its overall impact on our economy has been quite depressing. Although it would be illogical to blame neoliberalism for all "wrongs," of course, since political developments in India and China, coupled with our own economic policies may have their role in it. However, despite some benefits in service and technology sector, otherwise, neoliberalism which expands on the base of globalization seems to have done more harm than good to our economy. This, however, would be a picture far from correct and it would be unfair not to objectively analyze the issue from different vantage points.

An equitable school of thought of globalization is authenticated by Amartya Sen's "How to Judge Globalism". Building upon the exuberance of proponents, he approves of immense possibilities and opportunities of globalization, and formulates his reasoned defense that it is not a "new Western curse". Drawing upon the discontents of the opponents of globalization, he proclaims that globalization is conspicuously unjust in its consequences. To him, the primary concern is to reassess and restructure the global arrangements and institutions to make it possible for a more equitable distribution of its potential benefits and rewards.

Almost a rebuttal of anti-globalization, Amartya Sen posits that globalization is not a "new Western curse". He views that globalization has played a pivotal role to develop the world through migration, travel, trade, and spread of knowledge, science and technology. The global interactions and interconnectedness over thousands of years have yielded to progress and development in many countries. As a result, the agents of globalization often have their origins far from the West. Amartya Sen illustrates that the advanced technology in the 1000 A. D. consisted of paper, printing press, gunpowder, the magnetic compass, the iron-suspension bridge, the kite, the wheelbarrow, and the rotary fan. These items were invented and produced in China, and later spread all over the world through globalization. A comparable example was the emergence and development of decimal system in India between the second and sixth centuries. Soon after, it was followed by Arab mathematicians. This innovation spread to Europe in the last quarter of the tenth century. These pieces of historical evidence corroborate that globalization is not the origin of the West, and not new. Globalization is also not connected to the Western imperialism. Had Europe not welcomed these innovations, it would have been economically, culturally and scientifically backward. So, Sen adds:

The agents of globalization are neither European nor exclusively Western, nor are they necessarily linked to Western dominance. Indeed, Europe would have been a lot poorer - economically, culturally, and scientifically - had it resisted the globalization of mathematics, science, and technology at that time. (p. 20)

Amartya Sen has correctly calculated the potential role of globalization to elevate the status of the economically disadvantaged and the down-trodden mass. He believes that to view globalization merely as Western imperialism is a fatal mistake. It would not have been advantageous to European countries, if they had resisted the globalization of mathematics, and technology in the first millennium. Thus, he suggests:

To see globalization as merely Western imperialism of ideas and beliefs ... would be a serious and costly error, in the same way that any European resistance to Eastern influence would have been at the beginning of the last millennium. (p. 21)

Apparently, he does not attribute any problems to globalization as he has realized immense advantages that globalization can offer to people of the Third World. It has been lucrative to different countries through migration and travel over hundreds of years. To Amartya Sen, it is not a recent phenomenon, but a historical process that has supplied great opportunities and benefits in the past and does so in the present time. He insists:

Globalization is a historical process that has offered an abundance of opportunities and rewards in the past and continues to do so today. The very existence of potentially large benefits makes the question of fairness in sharing the benefits of globalization so critically important. (p. 24) 
On the contrary, globalization is more concerned with the expansion of global market than with the establishment of democracy, expansion of elementary education, and the improvement of opportunities of marginalized class. He thinks that the primary problem is related to inequality in international and in international distribution. He sees that it is flagrantly unjust in distributing wealth between affluent and poor countries and among different groups within a country. So, he confirms: "A crucial question concerns the sharing of the potential gains from globalization between rich and poor countries and among different groups within a country" (p. 21). Admitting the issues raised by anti-globalization protestors, he reasons that it is mandatory to reassess and restructure the national and global institutional arrangements to facilitate the equitable distribution of opportunities and rewards of globalization. Ultimately, he recapitulates that globalization "deserves a reasoned defense, but it also needs reform" (p. 24).

Globalization, though largely portrayed as a new form of colonization, has also served as a platform to incorporate diverse reading and writing practices in the academia. The unrestricted traffic of verbal and written texts across different physical and cultural locations provides space and opportunity for different modes of teaching and learning practices. For example, in a writing classroom it allows the tacit permission to students to freely practice writing in their vernacular language. With the accelerated pace of information and infrastructural technology, the world has shrunk into a global village in which many classrooms have turned into a multicultural and multilingual spaces.

These diverse academic sites merit the use of different varieties of English language and compel the interlocutors to engage in the process of negotiation as they try to make sense of each other's' use of the language in getting the messages across. This has also helped dismantle the notion of standard language ideology by freely endorsing multimodal composition practices in a writing classroom. Talking about the mode of composition that can be used for communication, Suresh Lohani (2019) in "The history of multimodal composition, its implementation, and challenges" states that "which mode of communication is to be used is determined by the rhetorical situation, and that modes of communication beyond conventional discursive language nurture the potential to challenge the dominant values." (p. 123). Therefore, globalization that incorporates inclusivity positively impacts the writing practices in a writing classroom by creating room for different modes of composition practices. Similarly, Ashok Bhusal (2019), critiques current teaching practices of first-year composition instructors in US colleges and universities, stating that first-year composition is still dominated by monomodal practices. Therefore, it is important that we use multimodal assignments in first-year composition so our students can use their linguistic resources to make sense or their own worlds. Bhusal says, "The emergence of new tools and technologies in the twenty-first century has provided students with more opportunities to communicate in new ways using all the existing strategies for persuasion" (p. 171). It is important that we switch our "pedagogical focus from alphabetic writing to multimodal writing." (p. 171).

Globalization also tacitly calls for the approval of dialects in the mainstream writing practices that are largely conditioned by academic English. Suresh Lohani (2019) in "Constructing non-traditional rhetoric: Critical Study on Gloria Anzaldua and Suresh Canagarajah" states that "English, whether Metropolitan or World, has become hybrid too and one of its strengths is its ability to adapt and accommodate as per the shifting contexts and cultural territories it finds itself rolling into."(p.118). Lohani clearly speaks of how with the global openness and increasing academic institutions' acceptance of linguistic varieties across the world, "pure" academic English is already an obsolete notion. Globalization has thus helped rupture the hegemony of standard language ideology and proved instrumental in making writing classrooms more equitable by endorsing the strands of English practices by those positioned on the margin. Thus, despite the accusation globalization faces of promoting colonial values in the façade of liberalism, its contribution in creating writing classrooms based on socially just principles.

Globalization and feminism share some basic principles in that both encourage inclusive practices in differing forms. Ashok Bhusal (2107), in "Emphasizing the suppression of feminist voices," highlight "women rhetoricians from the prior four centuries, including seventeenth-century English writer Mary Astell, eighteenth-century English author Mary Wollstonecraft, the nineteenth-century American writer Margaret Fuller, and the later nineteenth and early twentieth-century African American writer Ida Bell Wells" (p. 54) to "reclaim their contributions in the twenty-first century" (p. 56). Though, there are many efforts to make our society very inclusive, there are still discriminatory practices. Therefore, as Ashok Bhusal (2017), in his "The rhetoric of racism and anti-miscegenation laws in the United States" states that "What is necessary at this point is, with the tools offered in critical race theory, is to complete a deeper study of minorities and bring their stories, their voices, into academic scholarship. Using personal (counter) narratives, increasing exposure to multicultural education, and incorporating the study of all minorities in critical race theory may prove to be effective practices in the effort to overcome the racism that many 
say is still prevalent in American society" (p. 88). With the increasing influence of globalization, we need to pay attention to the elements of critical race theory. It means we need to discuss "the racist attitudes and behaviours of the majority that have caused many problems for the marginalized "("The rhetoric of racism in society," p. 114).

In conclusion, globalization is the set of processes that involves growing diffusion, becoming interdependent, establishing transnational institutions, expanding global market, fostering world culture and consciousness, and disseminating discontents of globalization. A positive school of thought by Micklethwait and Wooldridge highlights that globalization secures freedom, enhances individual identity, and provides both producers and consumers abundant choices and advantages. The anti-globalization thought cherished John Gray views globalization as a Utopia whose pursuit has caused great human suffering, incurred social costs and rendered economies and political systems around the world unstable. In the midst of these two extreme schools lies the equitable school of thought advocated by Amartya Sen who builds a reasoned defense of globalization. These three schools encapsulate all the aspects of globalization, and are of paramount significance. But what is of great significance is that correcting the evils and making good use of the good in globalization should be mantra for today, for "globalization is here to stay" (Kupchan, 62) and as stated by George Soros in "From the Great Transformation to the Global Free Market," "the collapse of the global marketplace would be a traumatic event with unimaginable consequences." (quoted in Gray, p.22). In the teaching context, as discussed by Ashok Bhusal (2010), "instructors have to encourage students to find out the reasons of their writing, the subject they are talking about, and the participants in these interactions to make them aware of the genre expectations" (p. 13). In addition, instructors should make their students aware of different cultures as well.

\section{References:-}

1. Bhusal, A. (2019). Addressing FYC instructors' lack of technological expertise in implementing multimodal assignments. In Marginalia in Modern Learning Contexts (pp. 166-186). IGI Global.

2. Bhusal, A. (2017). Emphasizing the Suppression of Feminist Voices. International Journal of Humanities and Cultural Studies 4(2), 53-57.

3. Bhusal, A. (2010). Genre awareness in the writing center. MA Thesis, Department of English, Eastern Illinois University, Illinois.

4. Bhusal, A. (2017). The Rhetoric of racism and anti-miscegenation laws in the United States. IAFOR Journal of Arts and Humanities. 4(2).

5. Bhusal, A. (2019). The rhetoric of racism in society. Journal of Research Innovation. 9(1).

6. Duggan, L. (2012). The twilight of equality? Neoliberalism, cultural politics, and the attack on democracy. Beacon Press. IAFOR Journal of Arts \& Humanities, 4(2), 83-89.

7. Gray, J. (2015). False dawn: The delusions of global capitalism. Granta Books.

8. Kupchan, A. C. (2012). The democratic malaise: Globalisation and the threat to the West. Foreign Affairs. Ed. Rose, Gideon. Council of Foreign Affairs, 91, 62-67.

9. Lechner, Frank J. and John Boli. Introduction. The Globalization Reader. By Lechner and Boli. Ed. Frank J. and John Boli. $3^{\text {rd }}$ ed. Oxford: Blackwell Publishing, 2008. 1-5.

10. Lohani, S. (2019). The History of Multimodal Composition, Its Implementation, and Challenges. The Criterion: An International Journal in English 10 (1).

11. Lohani, S. (2019). Constructing Nontraditional Rhetoric: Critical Study on Gloria Anzaldua and Suresh Canagarajah. Journal of Research Innovation, 9 (1).

12. McKnight, J. L. (1984). John Deere and the bereavement counselor. Bulletin of Science, Technology \& Society, 4(6), 597-604.

13. Micklethwait, J. and Wooldridge, A. "The Hidden Promise: Liberty Renewed." Ed. Frank J. Lechner and John Boli. The Globalization Reader. $3^{\text {rd }}$ ed. Oxford: Blackwell.

14. Riedner, R. C. (2015). Writing neoliberal values: Rhetorical connectivities and globalized capitalism. Springer.Publishing, 2008. 11-18.

15. Sen, A. (2008). How to Judge Globalization. Ed. Frank J. Lechner and John Boli. The globalization reader. $3^{\text {rd }}$ ed. Oxford: Blackwell Publishing. 19-24.

16. Steger, M. B. (2008). Globalization: A Very Short Introduction. Oxford: OUP, 2003.Lechner, Frank J. and John Boli. The Globalization Reader. $3^{\text {rd }}$ ed. Oxford: Blackwell Publishing.

17. Stiglitz, J. E. (2002). Globalization and its discontents (Vol. 500). Norton: New York.

Bio: Arjun Kumal holds a Master's degree in English Studies from Pokhara University, Nepal. Kumal is a former journalist with Nepal Television. He has more than 18 years of experience working in the media, development 
communications, and advocacy. He is also a researcher, and his research interests are global socio-economic issues, pedagogy and diplomacy. 